\title{
Morphological and molecular characterization of a hybrid zone between Prosopis alba and P. nigra in the Chaco region of northwestern Argentina
}

\author{
Carmen Delcira Vega' ${ }^{1}$ Ingrid Teich ${ }^{1,2}$, Maria Cristina Acosta ${ }^{2,3}$, Diego Lopez Lauenstein ${ }^{1}$, Aníbal \\ Ramón Verga ${ }^{1}$, Andrea Cosacov²*
}

\begin{abstract}
${ }^{1}$ Instituto de Fisiología y Recursos Genéticos Vegetales, Centro de Investigaciones Agropecuarias-INTA. Camino 60 Cuadras Km 5 1⁄2 5119, Córdoba, Argentina.

${ }^{2}$ Laboratorio de Ecología Evolutiva - Biología Floral, Instituto Multidisciplinario de Biología Vegetal IMBIV, CONICETUniversidad Nacional de Córdoba, Córdoba, Argentina. CC495, CP 5000, Córdoba, Argentina.

${ }^{3}$ Facultad de Ciencias Exactas, Físicas y Naturales (Universidad Nacional de Córdoba), Argentina.
\end{abstract}

*Corresponding author: Andrea Cosacov, acosacov@imbiv.unc.edu.ar

\begin{abstract}
The Gran Chaco is the largest dry forest in South America. One of the key taxa of this biome is the genus Prosopis (Fabaceae) which contains several economically important species. One of the characteristics of this genus is its natural capacity to exchange genetic information among congeneric species, generating zones of high morphological and genetic variability at contact points. The study and management of these contact areas can contribute to the dynamic conservation of these native genetic resources. In this study, we analysed three sites within a gradient of land aridity, where $P$. nigra and $P$. alba grow in sympatry and apparently hybridize. This is the first study performed in both, Prosopis pure sites and hybrid swarm, which includes a spatially explicit approach and simultaneously analyses fruit and leaf morphological variation, together with molecular information (microsatellites markers). We performed a multivariate morphological analysis, Bayesian genetic clustering and multivariate associations between genetic and morphological variability in the pure parental populations and in the hybrid swarm, considering possible spatial autocorrelation. Bayesian cluster analysis revealed two distinct groups corresponding to each species, differentiating the pure morphotypes from sites 1 and 2 . Site 3, corresponding to the hybrid swarm, was composed of pure P. alba and P. nigra trees and hybrid individuals. We found morphological and molecular evidence of hybridization between P. alba and P. nigra, and detected novel phenotypes in the hybrid site.
\end{abstract}

Keywords: algarrobos, dry forest, hybridization, leaves, fruits, microsatellites, natural hybridization, variability.

\section{Introduction}

The Gran Chaco is the largest dry forest in South America and, unfortunately, one of the regions with the highest fragmentation and deforestation rates in the world (Volante et al., 2012, Hansen et al., 2013). One of the key taxa of this biome is the genus Prosopis (Fabaceae) which contains several economical and bio-cultural important species. Several Prosopis trees are of great value as multipurpose species in many arid and semiarid lands, with the potential to provide a wide range of products and to grow on the poorest soils, where few other useful species can survive (Pasiecznik et al., 2001, Verga 2005).

One of the characteristics of this genus is its natural capacity to exchange genetic information among congeneric species, generating zones of high morphological and genetic variability at contact points (Saidman 1990, Verga 1995, Vega \& Hernández 2005, Mottura 2006). These areas are often active sites of evolutionary changes in which hybridization and introgression may lead to increases in intraspecific genetic diversity, transfer of genetic adaptations, and even the emergence of new ecotypes or species (Goulet et al., 2017). It is generally assumed that hybridization plays an important role in adaptive 
evolution and speciation (Arnold \& Martin 2010). Thus, the study of these contact areas can contribute useful information to design intervention programs for the dynamic conservation of native genetic resources, enhancing species evolutionary capacity, and facilitating adaptation to changing environments (Eriksson et al., 1993).

Prosopis alba Griseb. is one of the most economically important native species of South America because of its excellent quality timber for the furniture industry. Due to its wide distribution, P. alba displays multiple zones of contact with different congeners throughout its geographic range. One of these congeneric species is $P$. nigra Griseb. which has good capacity to settle in highly degraded sites (Burkart 1976), supporting drier soils than $P$. alba. Its uses as timber resource are restricted because it is heavily attacked by wood boring insects, affecting wood quality. Previous studies on Prosopis hybridization were conducted using morphological characters (Palacios \& Bravo 1981, Joseau et al., 2013), isozymes and random amplified polymorphic DNA (RAPDs) (Saidman 1990, Verga 1995, Bessega et al., 2000a, Vega \& Hernandez 2005, Ferreyra et al., 2013), and recently with microsatellite markers (Mottura et al., 2005, Teich et al., 2015). Vega \& Hernandez (2005) studied a putative hybrid area between $P$. alba and $P$. nigra using morphological traits and RAPDs. However, due to the low number of sampled individuals they failed to confirm the hybrids origin nor could the spatial structuring at the genetic and morphological level be analysed.

In this study, we analysed three sites within a gradient of land aridity, where $P$. nigra and $P$. alba grow in sympatry and apparently hybridize. This co-distribution area provides a suitable natural experimental design for understanding hybridization between P. alba and P. nigra and its consequences at the phenotypic level. In addition, the sample size allowed us to evaluate the spatial structure and the association between genetic and morphological variation, which has been very useful in the study of other hybrid swarms of Prosopis (Teich et al., 2015). We hypothesize that hybridization between $P$. alba and $P$. nigra occurs in sympatric zones where there are morphologically intermediate trees blurring interspecific boundaries. Under this hypothesis, we expect to detect higher levels of morphological and genetic variation, and intermediate individuals between both parental species, in a putative hybrid site compared to pure parental sites.

Here we address the following specific questions: (1) what is the extent of foliar and fruit morphological variation among individuals from pure parental and putative hybrid sites? (2) What is the magnitude of the coupling/decoupling between foliar and fruit variability within sites? (3) Is there an association between morphological and genetic variability? (4) Does genetic and morphological evidence support the existence of a hybridization area between P. alba and P. nigra? (5) Are genetic and morphological variations spatially structured within sites? Answering these questions will allow us to advance in a greater research program which intends to approach the microevolutionary processes underlying morphological and genetic variability of Prosopis species in the Chaco phytogeographic region.

\section{Materials and Methods}

\section{Study species}

Prosopis alba and P. nigra are diploid species that belong to the Algarobia section, which contains most economically important species (Burkart 1976). P. alba is a tree of 5-15 m high with scarce and small spines. Leaves are rather large with a petiole of $0.5-8 \mathrm{~cm}$ long and pinnae of 6-14 cm long, with 25 to 50 pairs of leaflets separated for 1.5-6 mm. Legumes are yellow, straight or falcate to ring-shape and measure $12-25 \mathrm{~cm}$ long $x 11-20$ $\mathrm{mm}$ width (Burkart 1976). Prosopis nigra is a tree of 4-10 m high, with a dark bark, with axillary spines when present. Leaves are medium-size and pinnae measure $5-10 \mathrm{~cm}$ long, having 20-30 leaflets, distant not more than their own width. Legumes are yellow tinged with violet, straight or slightly subfalcate, thick and submoliniforme of $10-16 \mathrm{~cm}$ long $\times$ 0.7-0.9 width (Burkart 1976).

Flowers are protogynous and are grouped in inflorescences. A previous study on the mating system in some Prosopis species, which included P. alba and P. nigra (Bessega et al., $2000 \mathrm{~b}$ ) indicated that they are mostly outcrossers (although selfing can occur in these species). Pollination in Prosopis is made by insects and seed dispersal is endozoic, both strategies are usually associated to limited dispersal. In fact, in P. alba the average pollen dispersal distance was estimated to be between 5.36 and $30.92 \mathrm{~m}$ (Bessega et al., 2012).

\section{Study sites and sampling}

The study was carried out near Santa Victoria town, in Salta province, northwestern Argentina. Three discontinuous sites were sampled (Fig. 1): sites 1 and 2, where pure trees of $P$. alba and $P$. nigra were present, respectively, and site 3 , a zone where trees with both intermediate and pure morphotypes were found (i.e. a putative hybrid swarm). Site 1 and 2 are separated by $280 \mathrm{~m}$, while site 3 is located at $3900 \mathrm{~m}$ of sites 1 and 2 . The three studied sites constitute patches of forest.

Taxonomic identifications of the specimens were based on Burkart (1976) and then confirmed with an exploratory analysis (Fig. S1). The three sampled sites are within the area of influence of Pilcomayo River; periodical river overflows generate areas with different frequencies of flooding and sediment contributions, depending on terrain height. Thus, the studied sites showed differences in microenvironmental conditions: site 1 was at a lower altitude and within a more humid area, whereas site 2 was in a higher area, less prone to flooding. Site 3 showed more within-site environmental variability, characterized by a gradient from a higher to a lower, flood-prone area in the Pilcomayo River basin. All the available trees in each site were sampled, resulting in a total of 172 sampled individuals: 15 trees from site 1, 19 from site 2 and 138 individuals from site 3. Each tree was tagged and georeferenced and a herbarium voucher was collected and identified with a number, location and collectors data. The herbarium vouchers were deposited in the herbarium of the Faculty of Agricultural Sciences within the Algarrobo Collection which belongs to the National Prosopis 

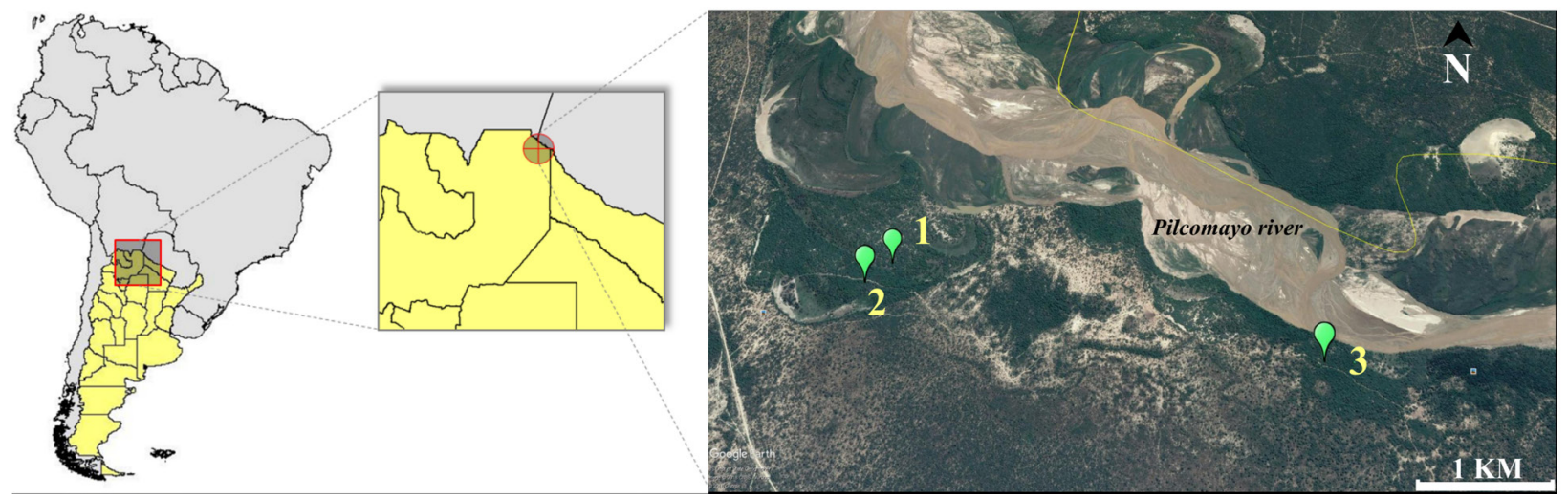

Fig.1

Map showing the geographical distribution of the three sites, two corresponding to the pure zones of $P$. alba (site 1) and $P$. nigra (site 2) and site 3 corresponding to the hybrid swarm, in Salta Province, northwestern Argentina.

Germplasm Bank (BNGP). The assigned voucher numbers are shown in Table S1.

\section{Leaf morphological traits}

For each tree, a total of nine leaf characters usually used for species identification (Burkart 1976; Pasiecznik et al., 2001; Bessega et al., 2009) were measured in five totally expanded leaves obtained from different canopy regions. All morphological leaf traits were recorded on photographs taken to fresh material collected in the field: petiole length (PEL), number of pairs of pinnae (NPI), pinna length (PIL), number of pairs of leaflets per pinna (NLP), leaflet length (LEL), leaflet width (LEW), leaflet area (LEA), leaflet apex area (LAPX), and leaflet apex/total area (LAPX/LEA) (Fig. 2a). All measurements were taken using the software HOJA 3.4 (available from the author upon request: $A$. Verga, INTA-IFRGV). Based on Burkart (1976) and in leaf traits, we classified each tree a priori as $P$. alba (with more than two pinnae, longer petiole length, longer and wider leaflets), P. nigra (short petiole, small leaflets, less than two pinnae, short pinnae) or as an intermediate morphotype (putative hybrid).

\section{Fruit morphological traits}

Five pods per tree were collected and stored in cloth bags treated with insecticide until measurement. Fruits were found only in 80 of the 172 sampled trees. The characters fruit length (FrL), fruit width (FrW) and fruit thickness (FrTh) were measured using a digital calliper (Fig. 2b). Based on Burkart (1976) and Palacios \& Brizuela (2005) fruits were classified according to their shape (FSh) as: straight (class 1); curved in a single plane (class 2) and twisted (class 3). Fruit edge shape (FESh) was characterized as: straight, without strangulations (class 1); straight with some strangulation (class 2); strangulations all along the edge (class 3); rosary form (class 4). Fruit colour (FrC) was classified as: uniform yellow (class 1); yellow with some violet spots (class 2); numerous violet spots on a yellow background (class 3); totally black (class 4). The classes of the last three variables (FSh, FESh and $\mathrm{FrC}$ ) represent a continuum in shape (from straight to curly) and in colour (from yellow to black) and are therefore considered ordinal (Joseau et al., 2013). Additionally, each tree was classified based on fruit characters following
Burkart (1976) and Palacios \& Brizuela (2005) as a typical P. alba (light coloured, straight shape and edges) or P. nigra (darker fruit, more twisted and with strangulations).

a
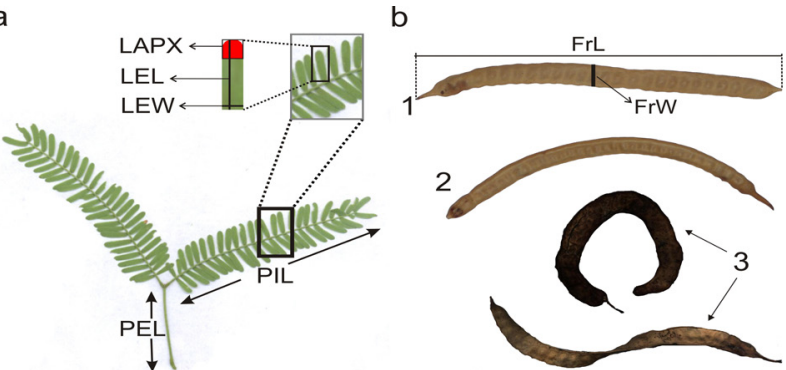

Fig. 2

Prosopis leaf (a) and fruit (b) morphological characters. Petiole length (PEL), pinna length (PIL), leaflet length (LEL), leaflet width (LEW), leaflet area (LEA), leaflet apex area (LAPX), fruit length (FrL), fruit width (FrW) and fruit thickness (FrTh). Fruit shape (FSh) was classified as: straight fruits (class 1); curved fruits in a single plane (class 2) and spiraled fruit (class 3 ).

\section{DNA extraction and microsatellite genotyping}

Total genomic DNA was isolated from silica-gel dried leaf tissue obtained from a subset of 74 trees representative of the morphological variation in each site (nine trees from site 1, fourteen from site 2 and 51 from site 3) using the genomic DNA purification kit (NucleoSpin Plant II). Five SSR markers were used, three developed by Mottura et al., (2005), which were successfully tested in P. nigra (Mottura et al., 2005) and in P. alba (Bessega et al., 2009), and two developed specifically for P. alba by Bessega et al., (2013) (Table 1). Each forward primer was labelled with a fluorescent dye (6-FAM or HEX) at its $5^{\prime}$ end, whereas the reverse primers remained unlabelled.

For the primers developed by Mottura (Mo08, Mo13 and Mo05), the PCR amplifications were carried out in a $15-\mu$ reaction volume containing $10 \mathrm{ng}$ template DNA, $1.5 \mathrm{mM}$ of $\mathrm{MgCl}$, $10 \mathrm{mM}$ Tris-HCL pH 9.0, $50 \mathrm{mM} \mathrm{KCL}, 0.15 \mathrm{mM}$ of each dNTPs, 0.5 units of taq DNA polymerase, and $0.6 \mu \mathrm{m}$ of each primer. Thermal cycler (Mastercycler Gradient Eppendorf) was set with the 
Table1

Description and characteristics of the five genomic microsatellites loci used in this study

\begin{tabular}{|c|c|c|c|c|}
\hline Locus & $\begin{array}{l}\text { Fragment } \\
\text { size }\end{array}$ & Primer sequence & $\begin{array}{l}\text { Reason of } \\
\text { repetition }\end{array}$ & $\begin{array}{l}\text { GenBank } \\
\text { accession }\end{array}$ \\
\hline \multirow[t]{2}{*}{ Mo08 $^{1}$} & $211-221$ & F:TATCCTAAACGCCGGGCTAC & $(\mathrm{AC})_{9}$ & AJ879507 \\
\hline & & R:TCCCATTCATGCATACTTAAACC & & \\
\hline \multirow[t]{2}{*}{ Mo13' } & $223-239$ & F:TTGATTAGAGTTGCATGTGGATG & $(\mathrm{GT})_{10} \mathrm{CT}(\mathrm{GT})_{2}$ & AJ879509 \\
\hline & & R:TGCAGTCCCAAGTGTCAGAG & & \\
\hline \multirow[t]{2}{*}{$\mathrm{GL} 6^{2}$} & $203-237$ & F:CTGGTTGCTGTGATTGGAGG & $(\mathrm{GAT})_{7}$ & $J \times 136854$ \\
\hline & & R:CTCCAGGGATCACAAGACAAAC & & \\
\hline \multirow[t]{2}{*}{ GL8 ${ }^{2}$} & $171-189$ & F:CAGGTGGGCATGAAGTTTCC & $(\mathrm{AT})_{12}$ & $J X 136855$ \\
\hline & & R:CCAAGAACAACCTGCCGAAG & & \\
\hline \multirow[t]{2}{*}{$\mathrm{MO}^{1}$} & $215-219$ & F:AATTCTGCAGTCTCTTCGCC & $(\mathrm{CT})_{3} \mathrm{~T}(\mathrm{CT})_{2}$ & JX136857 \\
\hline & & R:GATCCCTCGTGACTCCTCAG & & \\
\hline
\end{tabular}

${ }^{1}$ Mottura et al. 2005; ${ }^{2}$ Bessega et al. 2013

following cycling profile: initial denaturation at $94^{\circ} \mathrm{C}$ for $5 \mathrm{~min}$ followed by 30 cycles of denaturation at $94^{\circ} \mathrm{C}$ for $45 \mathrm{~s}$, primerspecific annealing temperature $\left(58-64^{\circ} \mathrm{C}\right)$ for $45 \mathrm{~s}$, and primer extension at $72{ }^{\circ} \mathrm{C}$ for $45 \mathrm{~s}$, followed by a final extension step of $10 \mathrm{~min}$ at $72{ }^{\circ} \mathrm{C}$. For primers developed by Bessega et al., (GL6 and GL8), PCR amplifications were carried out in a $25-\mu$ reaction volume containing 10-30 ng DNA, $0.6 \mu \mathrm{M}$ each primer, 0.2 mM dNTPs, $0.3 \mathrm{U}$ Taq DNA polymerase (Invitrogen, Buenos Aires, Argentina). The cycling profile was: an initial denaturation at $94{ }^{\circ} \mathrm{C}$ for 5 min followed by 30 cycles of denaturation at $94{ }^{\circ} \mathrm{C}$ for $45 \mathrm{~s}$, primer-specific annealing temperature (58-62 ${ }^{\circ} \mathrm{C}$ ) for $45 \mathrm{~s}$, and primer extension at $72{ }^{\circ} \mathrm{C}$ for $45 \mathrm{~s}$ followed by a final extension step of $10 \mathrm{~min}$ at $72^{\circ} \mathrm{C}$. PCR products were electrophoresed in an ABI 313 XL automated DNA sequencer (HITA$\mathrm{CHI}$ ) and analysed with the software GENEMARKER version 1.91 (SoftGenetics LLC ${ }^{\text {TM}}$ ).

\section{Data analysis}

\section{Morphological variability}

The variation of foliar morphological traits was analysed in the full data set $(n=172)$, whereas for fruit variability the subset of trees bearing fruits was used $(n=80)$. The mean and standard errors of each of the nine leaf variables were calculated for each individual and each site and an analysis of variance (ANOVA) was performed for comparison among sites. To visualize the ordination of individuals according to their morphological variability, two Principal Components Analyses (PCA) were performed: (1) on the 172 trees and the nine variables used for leaf morphological characterization and (2) on the 80 trees and the six variables used for fruit morphological variability. Then, biplots were obtained and individuals were identified by the site of origin. Additionally, two Linear Discriminant Analysis (LDA) were performed (one for fruit and another for the leaf data set). LDA is a supervised statistical learning technique which, unlike unsupervised methods such as cluster analysis, uses a priori knowledge about which observation belongs to which group. LDA tests the hypothesis that groups could be reconstructed based on the available set of predictors. LDA involves the determination of a linear equation, the discriminant function (DF), which is used to predict which group an observation belongs to. In the present study, the predictors were leaf or fruit traits and each tree was re-classified according to its foliar traits (group 1: P. alba leaves, group 2: P. nigra leaves, group 3: intermediate leaves, i.e. putative hybrids) or fruit traits (P. alba fruit or $P$. nigra fruit, because no intermediate fruits were found), respectively. The two classifications obtained with the LDA (regarding foliar and fruit traits) were compared with a cross classification table and a Chi square test. Additionally, the association between leaf and fruit morphological variations was analysed using a Generalized Procrustes Analysis (Gower 1975) performed with the subset of the 80 trees characterized by both fruit and leaf traits. The significance of this analysis was tested via permutations with the function protest in the vegan library (Oksanen et al., 2011) of R (Development Core Team, 2012). The Procrustean association metric (a vector of Procrustean residuals) was compared with an Analysis of variance (ANOVA).

\section{Genetic variability and structure}

Genetic variability and diversity in each site were quantified through the number of alleles per locus (A), percentage of polymorphic loci $(\mathrm{P})$, Shannon index of genetic diversity, and expected $(\mathrm{He})$ and observed $(\mathrm{Ho})$ heterozygosity with GenAlEx 6.5 (Peakall \& Smouse 2012). To consider the effect of different sample sizes in the estimation of genetic variability parameters, we randomly re-sampled 9 individuals of site 3 , obtaining 200 pseudo samples. For each re-sampled group of individuals all the genetic parameters were estimated and then a mean value for each estimator was calculated. Before performing genetic population structure analyses, Hardy-Weinberg Equilibrium (HWE) was tested for each locus/site, in order to detect an excess of homozygosis which can bias population structure 
analyses. When deviations from Hardy-Weinberg equilibrium was detected, we checked all loci for null alleles using MicroChecker 2.2.3 program (Van Oosterhout et al., 2004).

To estimate genetic differentiation among populations, pairwise $F_{S T}$ were calculated in GenAlex. To correct $F_{S T}$ values considering null alleles we used the ENA method implemented in FreeNa program (Chapuis \& Estoup 2014) with 30,000 bootstrap resampling. To visualize the ordination of all individuals studied, according to their genetic variability, a PCA was performed on the allele frequency data matrix using the dudi.pca function in ade4 library (Dray \& Dufour 2007) of the statistical program R. To select the number of components we considered not only the explained variance but also the distribution among eigenvalues in a scree plot (Teich et al., 2014).Then, biplots were obtained with InfoStat software (Di Rienzo et al., 2017) where individuals were identified according to their site of origin.

Finally, to estimate the number of genetic groups or clusters (K) we used the Bayesian analysis Structure 2.3.4 (Pritchard et al., 2000) by exploring values from $K=1$ to $K=6$. Each run consisted of 1000000-step ( $25 \%$ burn-in), with 10 iterations. We used the admixture model because it allows for mixed ancestry of individuals and the correlated allele frequencies model because it can improve clustering of closely related populations or species. The most likely number of groups (K) was chosen by comparing logarithmized probabilities of data $[\operatorname{Pr}(\mathrm{X} \mid \mathrm{K})]$ according to Pritchard et al., (2000) and by calculating an ad hoc statistic, $\Delta \mathrm{K}$, according to Evanno et al., (2005) with the Harvester program (Earl \& Vonhold 2012).

\section{Spatial structure of morphological and genetic variation within sites}

To detect spatial structure of morphological and genetic variation within each study site, Mantel tests (Mantel 1967) were performed to evaluate the significance of the correlation between morphological and spatial distances, and between genetic and spatial distances, among individuals within each site. These analyses were performed using the spdep library (Bivand et al., 2011) of the program R. For the genetic distance matrix we used the Euclidean distance among individuals based on the allele frequency data. As an additional analysis to detect spatial genetic structure within each site, Rousset (Rousset 2000) regression analyses between matrices of genetic differentiation and the natural logarithm of geographical distances were performed using the Genepop program (Rousset 2008). Finally, to visualize the spatial pattern of genetic variability, a synthetic map was built by interpolating the first component of the PCA performed on the allele frequency matrix (PC1g). We used the Multilevel B-spline algorithm for spatial interpolation (Lee et al., 1997) implemented in QGIS 3.2.1 (QGIS Development Team 2018).

\section{Association between genetic and morphological variation}

To evaluate the association between morphological and genetic variability we performed a partial Mantel test, which evaluates the correlation between the Euclidean genetic and morphological distance matrices while controlling the effect of the spatial autocorrelation by incorporating a matrix of spatial distances (Smouse et al., 1986). Additionally, we performed a Generalized Procrustes Analysis (GPA, Gower 1975) between the genetic and morphological matrices. The quantification of the consensus by generalized Procrustes analysis provides information about the harmonization or adaptation of the configurations produced by each set of variables. These analyses were performed using functions procrustes, protest and mantel.partial in vegan library (Oksanen et al., 2011) of R (Development Core Team, 2012).

\section{Results}

\section{Morphological variability}

Morphological characters varied among the three sites (Table 2). Intraindividual standard errors are presented in Table S2. The trait with the lowest within tree variability was LAPX, with a mean CV of $11 \%$, whereas PEL was the trait with highest level of intraindividual variability (mean $\mathrm{CV}=32 \%$ ). Variability at intra-individual level was on average, 20.43, 18.98 and 19.04 in site 1,2 , and 3 respectively (Table $\mathrm{S} 2$ ).

\section{Table 2}

Mean ( \pm SE.) and among sites ANOVA results for each leaf measured traits. Different letters indicate significant differences between sites (post hoc Tukey test $<0.05$ ); SE (standard error), PEL (petiole length), PIL (pinna length), NPI (number of pairs of pinnae), NLP (number of pairs of leaflets per pinna), LEL (leaflet length), LEW (leaflet width), LEA (leaflet area), LAPX (leaflet apex). The number of measured individuals within each site are indicated (n).

\begin{tabular}{lcccc}
\hline & $\begin{array}{c}\text { Site } 1 \\
(16)\end{array}$ & $\begin{array}{c}\text { Site } 2 \\
(19)\end{array}$ & $\begin{array}{c}\text { Site } 3 \\
(138)\end{array}$ & P(ANOVA) \\
\hline Leaf trait & & & & \\
$\mathrm{PEL} \pm \mathrm{SE}$ & $2.34 \pm 0.13^{\mathrm{a}}$ & $2.91 \pm 0.18^{\mathrm{ab}}$ & $3.27 \pm 0.08^{\mathrm{b}}$ & $\mathbf{0 . 0 0 1}$ \\
$\mathrm{PIL} \pm \mathrm{SE}$ & $9.83 \pm 0.34$ & $8.71 \pm 0.30$ & $9.58 \pm 0.18$ & 0.109 \\
$\mathrm{NPI} \pm \mathrm{SE}$ & $1.93 \pm 0.08^{\mathrm{b}}$ & $1.34 \pm 0.08^{\mathrm{a}}$ & $1.53 \pm 0.04^{\mathrm{a}}$ & $\mathbf{0 . 0 0 0}$ \\
$\mathrm{NLP} \pm \mathrm{SE}$ & $31.8 \pm 1.23^{\mathrm{b}}$ & $24.4 \pm 0.57^{\mathrm{a}}$ & $25.6 \pm 0.36^{\mathrm{a}}$ & $\mathbf{0 . 0 0 0}$ \\
$\mathrm{LEL} \pm \mathrm{SE}$ & $0.96 \pm 0.05$ & $1.00 \pm 0.04$ & $1.06 \pm 0.02$ & 0.060 \\
$\mathrm{LEW} \pm \mathrm{SE}$ & $0.18 \pm 0.01^{\mathrm{a}}$ & $0.18 \pm 0.01^{\mathrm{a}}$ & $0.21 \pm 0.00^{\mathrm{b}}$ & $\mathbf{0 . 0 0 0}$ \\
$\mathrm{LEA} \pm \mathrm{SE}$ & $0.17 \pm 0.01^{\mathrm{ab}}$ & $0.16 \pm 0.01^{\mathrm{a}}$ & $0.20 \pm 0.01^{\mathrm{b}}$ & $\mathbf{0 . 0 0 3}$ \\
$\mathrm{LAPX} \pm \mathrm{SE}$ & $0.15 \pm 0.00^{\mathrm{a}}$ & $0.16 \pm 0.00^{\mathrm{b}}$ & $0.15 \pm 0.00^{\mathrm{c}}$ & $\mathbf{0 . 0 0 0}$ \\
$\mathrm{LAPX} / \mathrm{LEA} \pm \mathrm{SE}$ & $0.84 \pm 0.01$ & $0.89 \pm 0.03$ & $0.85 \pm 0.01$ & 0.415 \\
\hline
\end{tabular}

The first two principal components (PC1 and PC2) obtained from the analysis of the leaf morphological traits explained $58.3 \%$ of the total variability among individuals (Fig. 3a). High values of PC1 (which accounted for $36.4 \%$ of the total variability) were related to large leaflet sizes, since LEL, LEA and LEW were positively correlated to this axis. Long petioles and pinnae (PEL and PIL) were also related to high values of PC1 
(Fig. 3a). PC2 was positively related to number of leaflets and pinnae (NPI, NLP), accounting for $21.9 \%$ of the total variability. This axis differentiated pure $P$. alba individuals (site 1) from pure $P$. nigra individuals (site 2 ), which showed lower numbers of pinnae and leaflets (lower PC2 values) than the former. Site 2 also presented more variability along PC1 (related to leaflet size) than site 1 . As expected, trees from site 3 showed more variability than pure morphotypes, both in PC1 and PC2 (Fig. 3a). The total error rate of the LDA performed with the foliar traits was $23.7 \%$. In site 1 all individuals were classified as $P$. alba; in site 2, five trees were classified as $P$. nigra and 2 as intermediate; and in site 3,12 individuals were classified as P. alba, 23 as $P$. nigra and 27 trees as of intermediate leaf morphology.

Regarding fruit variability, PC1 and PC2 accounted for 56.9 $\%$ and $16.5 \%$ of the total variability among individuals, respectively (Fig. 3b). In contrast to leaf morphological characters, two groups were clearly identified along PC1. One group, which consisted of all trees from site 1 and included some trees from site 3, presented positive PC1 values, with individuals characterized by large light-coloured fruits of straight edges. Instead, all trees from site 2 and some trees from site 3 presented negative PC1 values, with individuals characterized by dark-coloured, shorter and more strangulated fruits. As expected, the total error rate of the LDA performed with the fruit traits was $0 \%$, since fruits were clearly differentiated into two groups. In site 1 all individuals were classified as $P$. alba, in site 2 all individuals were classified as P. nigra, and in site 3, 29 individuals were classified as $P$. alba and 33 as $P$. nigra.
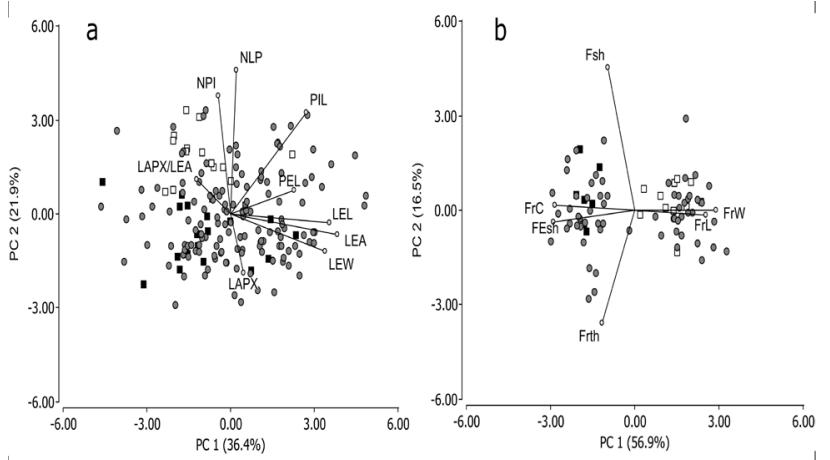

$\square$ Site $1 \square$ Site $2 \bigcirc$ Site 3

Fig. 3

Principal Component Analysis (PCA) of (a) leaf and (b) fruit morphological characters of 172 Prosopis individuals. Different colours and symbols represent the three sites (Site 1: P. alba; Site 2: P. nigra and site 3: intermediate morphotypes).

The cross-classification table, built with the fruit and leaf classifications retrieved from LDA analyses, is shown in Table 3. The obtained Chi square statistic indicated a strong association between both classifications $\left(x^{2}=37.6, p<0.001\right)$. Almost half of the trees with intermediate leaves (14 individuals) had $P$. alba fruits, whereas the remaining 17 trees had $P$. nigra fruits. All of the 23 trees classified as $P$. alba based on foliar traits presented a typical P. alba fruit. However, of the 28 trees classified as P. nig$r a$ based on leaf traits, three had $P$. alba fruits. In this line,
Table 3

Cross classification table of the 80 measured individuals from the three study sites, derived from a Linear Discriminant Analyses using leaf and fruit morphological traits.

\begin{tabular}{lcc}
\hline & P. alba fruits & P. nigra fruits \\
\hline P. alba leaves & 23 & 0 \\
P. nigra leaves & 3 & 23 \\
Intermediate leaves & 14 & 17 \\
\hline
\end{tabular}

regarding the association between leaf and fruit morphological variation, there was a significant concordance between the ordinations of trees based on fruit and foliar traits, according to the GPA ( $p=0.0001)$. The total proportion of consensus was 67 $\%$. The consensus between leaf and fruit morphological variation was $74 \%$ in site $1,66 \%$ in site 2 , and $62 \%$ in site 3 ; these values revealed the strongest association between fruit and leaf characters in P. alba pure morphotypes (site 1) and the lowest level of concordance in the putative hybrid swarm (site $3)$. However, these differences were not statistically significant $(p=0.13)$.

\section{Genetic variability and structure}

Microsatellite loci were highly polymorphic in the three sites, with a total number of 13, 21 and 41 alleles retrieved in site 1, site 2 and site 3, respectively. Average observed heterozygosity (Ho) ranged from 0.408 (site 2) to 0.481 (site 3) and the expected heterozygosity $(\mathrm{He}$ ) ranged from 0.456 (site 2 ) to 0.618 (site 3) (Table 4). The most polymorphic marker was the GL6, with 14 alleles. One private allele was detected in site 1 , two in site 2 and nine in site 3 . Of those nine private alleles of site 3 , three were exclusively found in P. alba (five individuals), one allele in $P$. nigra (three individuals), and one in a hybrid tree. The remaining four private alleles of site 3 were shared between $P$. alba and $P$. nigra, or between hybrids and one of the parental species.

Significant deviation from HWE was observed after Bonferroni correction $(P<0.05)$ in locus MO13 at sites 1 and 2 . However, the exclusion of this locus does not produce significant changes in global FIS and diversity estimates. In site 3, all loci resulted not at HWE after Bonferroni correction. In this site the presence of null alleles was detected in all loci except for the GL6.

Genetic differentiation among sites was significant $(p<0.001)$, with the greatest observed divergence between pure sites, site 1 and $2\left(\mathrm{~F}_{\mathrm{ST}}=0.305\right)$, whereas the hybrid site showed an intermediate differentiation $\left(\mathrm{F}_{\mathrm{ST}}=0.088\right.$ and 0.092 between sites 1 and 3, and between sites 2 and 3, respectively) (Table S3). In site 3, the estimation of between sites differentiation using the $F_{S T}$ without correction $\left(F_{S T}=0.1305\right)$ and with correction by null alleles $\left(F_{S T} E N A=0.1313\right)$ was similar.

This suggests that null alleles do not have an impact on the estimated parameters and therefore this set of markers can be used as independent markers to evaluate the genetic diversity and population structure in the studied system. 
Table 4

Parameters of genetic diversity for polymorphic loci per site. Na: observed number of alleles, Ne: effective number of alleles, Ho: observed heterozygosity, He: expected heterozygosity, I = Shannon's information Index

\begin{tabular}{|c|c|c|c|c|c|c|c|c|c|c|c|c|c|c|c|}
\hline \multicolumn{6}{|c|}{ Site 1} & \multicolumn{5}{|c|}{ Site 2} & \multicolumn{5}{|c|}{ Site 3} \\
\hline Locus & $\mathrm{Na}$ & $\mathrm{Ne}$ & Ho & $\mathrm{He}$ & 1 & $\mathrm{Na}$ & $\mathrm{Ne}$ & Ho & $\mathrm{He}$ & 1 & $\mathrm{Na}$ & $\mathrm{Ne}$ & Ho & $\mathrm{He}$ & 1 \\
\hline Mo08 & 4 & 2.3 . & 0.556 & 0.568 & 1.059 & 3 & 1.6 & 0.357 & 0.390 & 0.665 & 5.2 & 3.7 & 0.573 & 0.716 & 1.427 \\
\hline Mo13 & 3 & 2.9 & 0.667 & 0.654 & 1.268 & 4 & 1.7 & 0.286 & 0.403 & 0.761 & 6.1 & 4.0 & 0.551 & 0.737 & 1.548 \\
\hline Mo05 & 1 & 1.0 & 0.000 & 0.000 & 0.000 & 1 & 1.0 & 0.000 & 0.000 & 0.000 & 1.5 & 1.2 & 0.000 & 0.119 & 0.195 \\
\hline GL6 & 3 & 2.6 & 0.429 & 0.612 & 1.215 & 7 & 4.9 & 0.857 & 0.796 & 1.738 & 7.3 & 4.6 & 0.687 & 0.767 & 1.705 \\
\hline GL8 & 2 & 2.0 & 0.556 & 0.500 & 0.926 & 6 & 3.3 & 0.538 & 0.692 & 1.388 & 6.7 & 4.3 & 0.592 & 0.752 & 1.630 \\
\hline Average & 2 & 2.2 & 0.441 & 0.467 & 0.894 & 4 & 2.5 & 0.408 & 0.456 & 0.910 & 5.4 & 3.6 & 0.481 & 0.618 & 1.301 \\
\hline
\end{tabular}

The first and second axes of PCA (PC1 and PC2) performed on the allele frequency data matrix accounted for $31 \%$ and 8.1 $\%$ of the total variance, respectively (Fig. 4 a). According to their genetic similarity, some individuals belonging to site 3 were grouped with P. alba, others with P. nigra, and others presented intermediate positions.

The Bayesian clustering analysis performed with STRUCTURE revealed that the 74 samples from the three sites belong to two genetic groups (best $\mathrm{K}=2$ ) (Fig. 4b). Additionally, using the method developed by Evanno et al., (2005), the values of $\Delta \mathrm{K}$ peaked at $\mathrm{K}=2$ (Fig. S2). The structure plots showed substantial genetic differentiation among the three sampled locations, with sites 1 and 2 being exclusively composed of pure $P$. alba and $P$. nigra individuals, respectively. Instead, site 3 is composed of pure $P$. alba and $P$. nigra individuals and hybrid trees (Fig. 4b). The analysis evidenced that five individuals characterized as hybrid based on morphology were assigned as pure individuals (Bayesian posterior probability $>0.8$ ) of $P$. alba (three individuals) and $P$. nigra (two individuals); contrarily three individuals characterized as pure individuals based on morphology were hybrids individuals based on the genetic assignment $(\mathrm{BPP}<0.8)$ (Fig. 4b).

\section{Spatial structure of morphological and genetic} variation within sites

No spatial structure of genetic or morphological variability was found for the sites using Mantel test ( $p>0.05$; Table S4). The Rousset regression only revealed significant genetic spatial structure in site 3 (slope $=0.010,95 \%$ confidence inter$\mathrm{val}=0.0030-0.2229$ ). The spatial pattern of genetic variability in the two parental populations and in the hybrid swarm is shown in Fig. 5.

\section{Association between genetic and morphological variation}

The Partial Mantel test indicated a statistically significant association between morphological and genetic variation $(r=0.302$, $p=0.001$ ). The consensus between the morphological and genetic characterization calculated by the GPA was $75 \%$, and was statistically significant ( $p=0.001)$. The first axis of the GPA summarized $51.8 \%$ of the consensus variability and the second axis explained $24.8 \%$ (Fig. 6). The graph reveals a clear differentiation between individuals of site 1 and 2, corresponding to $P$. alba and $P$. nigra, respectively, and a great variability among the hybrid individuals of site 3 .

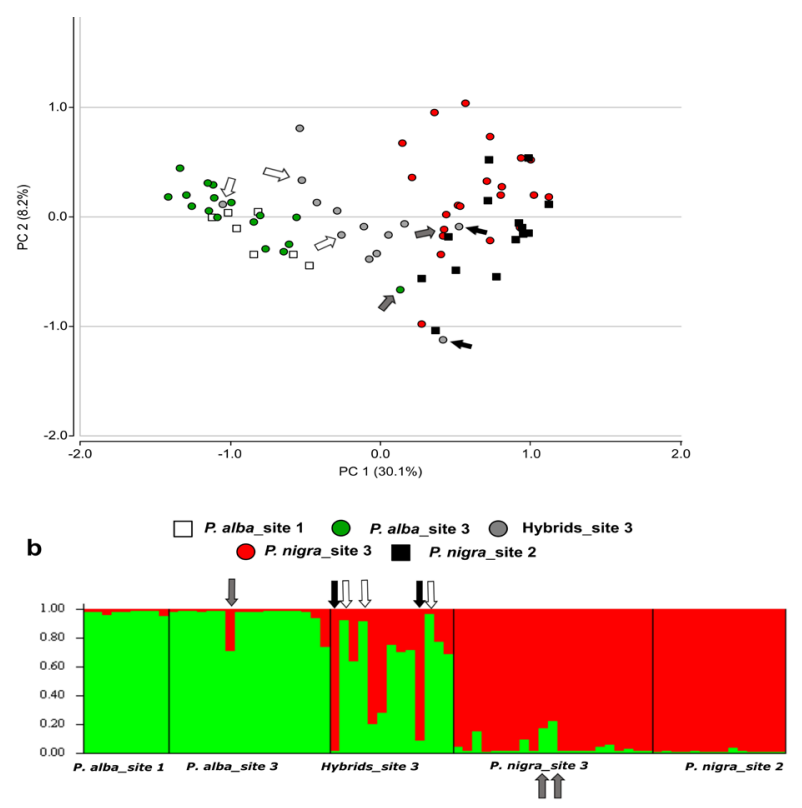

Fig. 4

Genetic characterization of the 74 study individuals from pure and hybrid sites. (a) Principal Component Analysis based on genetic data, individuals are coloured according to morphological classification in P. alba_site 1; P. alba_site 3; Hybrids_site

3, P. nigra_site 2 and P. nigra_site 3; (b) Genetic assignment of individuals and populations according to the Bayesian method implemented in the program STRUCTURE. Each thin vertical line represents an individual and the proportion of ancestry derived from each of the two main genetic group $(\mathrm{K}=2)$ inferred. Populations are separated by black vertical lines. Black and white arrows indicate individuals characterized as hybrids based on morphology, but identified as pure individuals of $P$. nigra and $P$. alba, respectively, based on genetic characters. Grey arrows indicate individuals characterized as pure individuals of $P$. nigra or $P$. alba based on morphology, but identified as hybrids individuals, based on genetic characters. 

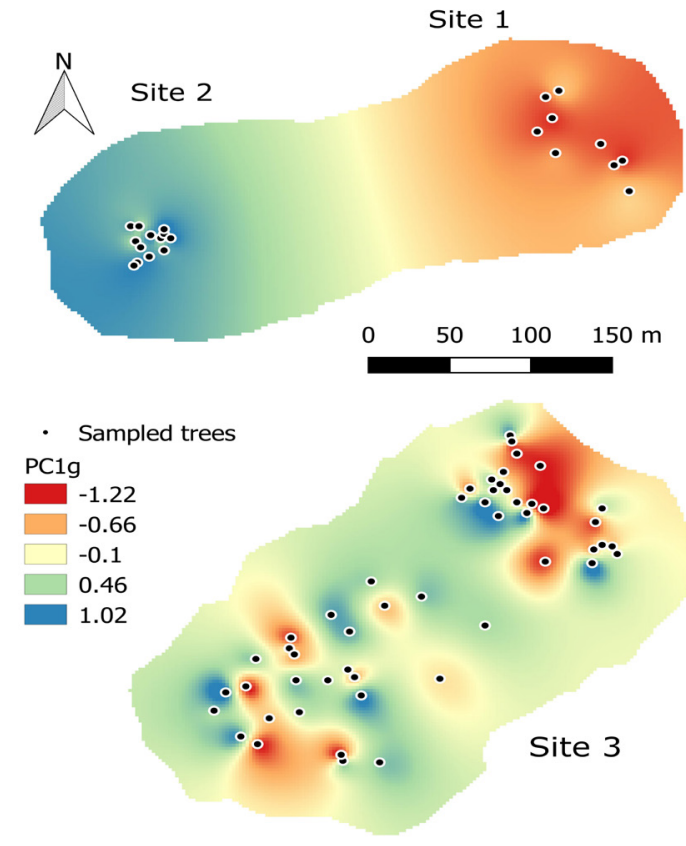

Fig. 5

Map obtained by interpolating the scores of the first principal component of a PCA performed on the allele frequency matrix. (a) P. alba (red, site 1) and P. nigra (blue, site 2) pure populations; (b) hybrid site (site 3).

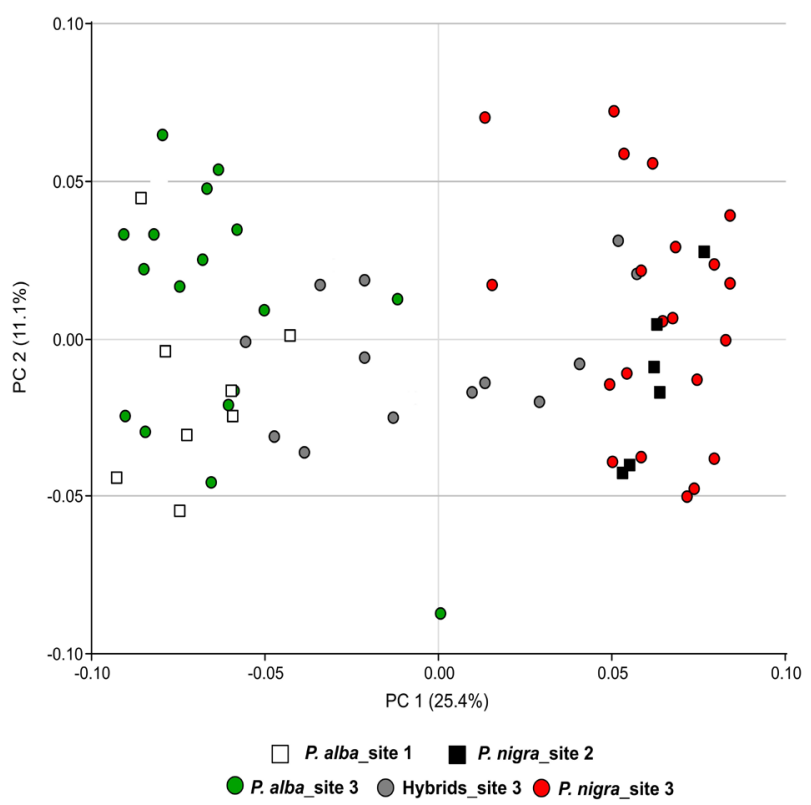

Fig.6

Consensus retrieved by Procrustes analysis between the morphological and genetic variability of 74 trees coloured by the five morphological groups.

\section{Discussion}

The present study was conducted in three sites, one corresponding to $P$. alba, another to $P$. nigra and the remaining one to a hybrid swarm where, in addition to the pure species, there were intermediate morphotypes between these two species. Thus, we considered it an appropriate system to characterize, first the morphological variation considering pure and intermediate individuals; second, a genetic characterization of the retrieved morphological groups; third, the spatial structure of morphological and genetic variation; and finally, the association between genetic and morphological variability. This is the first study performed in both, Prosopis pure species and hybrid swarm, which includes a spatially explicit approach and simultaneously analyses fruit and leaf morphological variation, together with molecular information.

The three analysed sites showed significant differences at the phenotypic level. In relation to leaf character variation, the first axis of the PCA summarizes size variation with the individuals of the hybrid site scattered along this axis (i.e. showing small and large leaves) and the pure individuals mainly restricted to the left portion of the PC1 (i.e. small leaves); meanwhile, the second axis of the PCA did retrieve information of taxonomic value, since $P$. alba and $P$. nigra diverged in relation to this axis, mainly correlated with the number of pinnae and folioles. A greater variability of hybrid individuals than that of their parents has been previously reported in other plant species, revealing the evolutionary potential of hybrid individuals (Campbell et al., 2018). Detecting higher phenotypic variability in the hybrid site is expected because the combination of both parental species gene pools. However, in previous Prosopis studies phenotypic variability was not different between the hybrid group and the putative parents (Ferreyra et al., 2013). In this line, we found that intraindividual variability was similar among sites, but phenotypic mean values did differ significantly among them. Within leaf traits, PEL presented the greatest intraindividual variability showing also significant differences among sites. These results agree with Ferreyra et al., (2013) who reported that PEL was the most variable leaf trait and suggested that most of PEL variation is environmentally determined.

Contrary to the observed in leaf variation, fruit variability did not show intermediate patterns, even in the hybrid area (site 3), as suggested by the PCA plot, which showed two divergent groups and the $0 \%$ error of the discriminant analysis performed on fruit traits and two groups: P. alba or P. nigra. One group consisted of large light-coloured fruits with straight edges (i.e. like fruits of $P$. alba), and the second one, consisted of small, dark and more strangulated fruits (i.e. like fruits of $P$. nigra). Quantitative leaf characters appear to be more susceptible to change as a result of hybridization than do fruit characters, as was observed in Quercus (Borazan \& Babaç 2003, Lopez de Heredia et al 2018). It has been reported that those morphological traits that are controlled by several genes might exhibit intermediacy in the hybrid, mainly F1 individuals, whereas those controlled by one or a few genes may exhibit novel or parental character states (Ferreyra et al., 2013; Goulet et al 2017). 
Considering fruit variation together with leaf variation, the discriminant analysis showed intermediate morphology in 43 $\%$ of the individuals of the hybrid area, whereas $19 \%$ of the trees were P. alba type and $37 \%$, P. nigra type. Thus, morphological evidence strongly supports site 3 as a putative hybrid area. As revealed by the cross-classification table, the individuals of the pure sites of $P$. alba and $P$. nigra have an evident morphological identity; indeed, the leaf type characteristic of $P$. alba corresponds to the characteristic fruit of this species, and the same applies to P. nigra. In the hybrid site we recovered intermediate phenotypes (almost half of the trees with intermediate leaves had $P$. alba fruits, whereas the remaining trees presented $P$. nigra fruits) and the corresponding pure parental morphotypes.

An interesting fact is that of the 26 trees classified as P. nig$r a$ in site 3 , based on leaf traits, three presented $P$. alba fruits. Thus, a decoupling in fruit and leaf type was observed in a few emerging individuals that had leaves of $P$. nigra and fruit of $P$. alba. However, the assignment based on molecular characters, indicated that two of them were pure individuals of $P$. alba and one was a pure individual of $P$. nigra. Therefore, despite these individuals are from the hybrid site (site 3 ) they would not be hybrids, at least based on the molecular markers used here. The inclusion of additional markers in future studies will allow us to conclude on the genetic status of these individuals. Anyway, according to the reviewed literature (Verga 1995, Joseau et al., 2013, Ferreyra et al., 2013), this is the first time that this type of decoupling has been detected in fruit and leaf characters in Prosopis. In this line, the Procrustean association metric between leaf and fruit characters retrieved the lowest value for site 3. In other hybridization studies carried out in $P$. chilensis and P. flexuosa (Verga 1995, Joseau et al., 2013, Teich et al., 2015), hybrids presented intermediate characteristics to both pure species; however, those studies did not report decoupling between fruit and leaf variables detected here. Although the novel phenotype appeared in few individuals in relation to the total sampled, the morphological decoupling between fruit and leaf variables, and the emergence of a novel phenotype give support to the importance of hybrid areas as active sites of evolutionary changes, in which hybridization may cause the emergence of new ecotypes or species (Goulet et al., 2017).

Genetic patterns revealed by the PCA and the Bayesian clustering analyses showed genetic differences between individuals from sites 1 and 2, taxonomically identified as $P$. alba and $P$. nigra, respectively. In site 3 , we detected "pure" individuals of both parental species and hybrids with different genetic similarity to $P$. alba or P. nigra. Molecular evidence also strongly supports site 3 as a hybrid zone: it was the site with the highest variability showing the highest number of alleles and of heterozygosity level and the $\mathrm{F}_{\mathrm{ST}}$ indicated an intermediate differentiation of this site and sites 1 and 2 . As occurred with the morphological data, PCA performed on the allele frequency data matrix retrieved individuals from site 3 that ranged widely between the two parental types. In this line, the Bayesian clustering analysis confirmed that site 3 is composed of pure $P$. alba and $P$. nigra trees and hybrid individuals between parental species. As pointed out previously (Saidman et al., 1998) unrestricted gene flow should reduce genetic differentiation among hybridising species, and produce continuous morphological variation, blurring species boundaries. Since we did not detect a morphological and genetic continuum in site 3 , hybridization and introgression would be low or too recent. Alternatively, hybrid individuals would produce offspring with reduced fitness, and (or) the high frequency of floods probably prevents these populations from developing into more than one or two generations.

Our results also show that the hybrid site was more variable both, morphologic and genetically, than pure sites. It is generally assumed that hybridization plays an important role in adaptive evolution (Arnold \& Martin 2010). In Prosopis, interspecific hybridization usually occurs more frequently in disturbed areas; hence, it is assumed that hybrids present differential adaptive characteristics with respect to the parental species and are therefore more adapted to the degraded environments in which these processes of genetic exchange take place. Thus, in this line, a relevant step is to detect spatial structure of morphological and/or genetic variation in the hybrid area, especially when it is located along an environmental gradient, as in the present study. Interestingly, the Rousset regression revealed significant genetic spatial structure in the hybrid area. The spatial genetic pattern visualized through the interpolation map, showed that trees more similar to $P$. alba are located towards the lower, flood-prone area in the Pilcomayo River basin but hybrids forms are distributed throughout the site 3. A possible explanation to the retrieved pattern is that hybridization did not result in individuals with intermediate physiological mechanisms, but with a unique trait combination allowing hybrids to survive under different conditions along the environmental gradient. This was proposed in a physiological study on Prosopis hybrids between $P$. chilensis and $P$. flexuosa (López Lauenstein et al., 2013), that showed that hybrids presented a higher growth rate when water availability is high (similar to the most vulnerable parental species) and, at the same time, a high survival under drought stress (similar to the most resistant parental species). Future greenhouse experiments in the study system will allow us to better explore this potentially adaptive variation.

Our study, which includes allopatric sites of $P$. alba and $P$. nigra (site 1 and 2 ) and a site where species are in sympatry (site 3 ), shows in both conditions similar and relatively low levels of genetic differentiation between pure species (one and three private alleles in allopatric vs sympatric sites, respectively), giving support to the idea that the high degree of interspecific genetic similarity and crossability should be explained by their relatively recent divergence rather than hybridization (Bessega et al., 2000b, Catalano et al., 2008).

\section{Conclusions}

It has been shown in different plant species that molecular and morphological assignments do not always correlate and that phenotypically intermediate individuals are the result of a 
wide intraspecific variation or convergent evolution rather than of hybridization (Goulet et al., 2017). In this study, the high correspondence between leaf morphology and genetic differentiation in the three sites confirms genetic and morphological differences between the two parental species and the existence of intermediate morphotypes, which correspond to interspecific hybrids. However, it is important to note that we detected a slight discrepancy between morphological and genetic assignments, since there were a few individuals that were identified as hybrids, based on morphological characters, being pure individuals according to the genetic characterization, and vice versa. These results suggest the morphological characters included in the present study are useful to differentiate between $P$. nigra and $P$. alba, as was proposed by Burkart (1976), but not to reliably distinguish between hybrid and pure individuals.

Our results are the initial step to understand the microevolutionary processes that take place in this contact zone between Prosopis alba and P. nigra and are fundamental to establish management and conservation units within this area. Future studies will focus on a comparison of contact zones between $P$. alba and different congeneric species, characterizing the adaptive value of the detected variability and of the novel phenotypes retrieved, as occurred in this studied area.

\section{Acknowledgements}

CD Vega, D Lopez Lauenstein and AR Verga are researchers at IFRGV-CIAP-INTA; I Teich, MC Acosta and A Cosacov are researchers at CONICET. We thank Jorgelina Brasca for reviewing the English language and two anonymous reviewers for their valuable comments on a previous version of the manuscript. This work was supported by INTA fundings: PNFOR-1104064 „Application of molecular tools to the use and conservation of forest genetic diversity", PNFOR-1104063 "Genetic improvement of high value native forest species", BIRF Project LN 7520 AR "Sustainable Management of Natural Resources" and "Sustainable Forest Plantations".

\section{References}

Arnold ML, Martin NH (2010) Hybrid fitness across time and habitats.Trends Ecology Evolution 25:530-536. https://doi.org/10.1016/j.tree.2010.06.005

Bessega C, Vilardi JC, Saidman BO (2000a) Isozyme and RAPD studies in Prosopis glandulosa and P. velutina (Leguminosae, Mimosoideae). Genetics and Molecular Biology 23: 639-648. https://doi.org/10.1590/s1415-47572000000300024

Bessega C, Ferreyra L, Vilardi JC, Saidman BO (2000b) Unexpected low genetic differentiation among allopatric species of section Algarobia of Prosopis (Leguminosae). Genetica 109:255-266.

Bessega C, Saidman BO, Darquier MR, Ewens M, Sanchez L, Rozenberg PH, Vilardi JC (2009) Consistency between marker and genealogy based heritability estimates in an experimental stand of Prosopis alba (Leguminosae). American Journal of Botany 96:458-465. https://doi.org/10.3732/ajb.0800074
Bessega C, Pometti CL, Miller JT, Watts R, Saidman BO, Vilardi JC (2013) New microsatellite loci for Prosopis alba and P. chilensis (Fabaceae). Applications in Plant Sciences 1:1200324. https://doi.org/10.3732/apps.1200324

Bivand R, Altman M, Anselin L, Assunção R, Berke O, Andrew B, Blanchet G, Blankmeyer E, Carvalho M, Christensen B, Chun Y, Dormann C, Dray S, Halbersma R, Krainski E, Legendre P, Lewin-Koh N, Hongfei Li JM, Millo G, Mueller W, Ono H, Peres-Neto P, Piras G, Reder M, Tiefelsdorf M, YD (2011) “spdep: Spatial dependence: weighting schemes, statistics and models. R package version 0.5-31."

Borazan A, Babaç MT (2003) Morphometric leaf variation in oaks (Quercus) of Bolu, Turkey. Annales Botanici Fennici 40:233-242.

Burkart A (1976) A monograph of genus Prosopis (Leguminosae subfam. Mimosidae). Journal of the Arnold Arboretum 57:219-249.

Campbell DR, Faidiga A, Trujillo G (2018) Clines in traits compared over two decades in a plant hybrid zone. Annals of Botany 122:315-324. https://doi.org/10.1093/aob/mcy072

Catalano SA, Vilardi JC, Tosto D, Saidman BO (2008) Molecular phylogeny and diversification history of Prosopis (Fabaceae: Mimosoideae). Biological Journal of the Linnean Society 93:621-640. https://doi.org/10.1111/j.1095-8312.2007.00907.x

Chapuis MP, Estoup A (2014) Microsatellite Null Alleles and Estimation of Population Differentiation. Molecular Biology and Evolution 24: 621-631. https://doi.org/10.1093/molbev/msl191

Dray S, Dufour AB (2007) The ade4 package: Implementing the duality diagram for ecologists. Journal of Statistical Software 22:1-20. https://doi.org/10.18637/jss.v022.i04

Di Rienzo JA, Casanoves F, Balzarini MG, Gonzalez L, Tablada M, Robledo, CW. InfoStat versión (2017) Grupo InfoStat, FCA, Universidad Nacional de Córdoba, Argentina.http://www.infostat.com.ar

Earl DA, Vonhold BM (2012) Structure Harvester: a website and program for visualizing STRUCTURE output and implementing the Evanno method. Conservation Genetics Resources 4:359-361. https://doi.org/10.1007/s12686-011-9548-7

Eriksson G, Namkoong G, Roberds JH (1993) Dynamic gene conservation for uncertain futures. Forest Ecology and Management 62:15-37. https://doi.org/10.1016/0378-1127(93)90039-p

Evanno G, Regnaut S, Goudet J (2005) Detecting the number of clusters of individuals using the software STRUCTURE: a simulation study. Molecular Ecology 14:2611-2620. https://doi.org/10.1111/j.1365-294x.2005.02553.x

Ferreyra LI, Vilardi JC, Verga A, López V, Saidman BO (2013) Genetic and morphometric markers are able to differentiate three morphotypes belonging to Section Algarobia of genus Prosopis (Leguminosae, Mimosoideae). Plant Systematics and Evolution 299:1157-1173. https://doi.org/10.1007/s00606-013-0786-x

Goulet BE, Roda F, Hopkins R (2017) Hybridization in Plants: old Ideas, New Techniques. Plant Physiology 173:65-78. https://doi.org/10.1104/pp.16.01340

Gower JC (1975) Generalized Procrustes analysis. Psychometrika 40:33-51. https://doi.org/10.1007/bf02291478

Hansen MC, Potapov PV, Moore R, Hancher M, Turubanova SA, Tyukavina A, Thau D, Stehman V, Goetz SJ, Loveland TR, Kommareddy A, Egorov A, Chini L, Justice CO, Townshend, JRG (2013) High-Resolution Global Maps of 21st-Century Forest Cover Change. Science 342:850-853. https://doi.org/10.1126/science.1244693

Joseau J, Verga A, Díaz MP, Julio N (2013) Morphological diversity of populations of the Genus Prosopis in the semiarid Chaco of Northern Cordoba and Southern Santiago del Estero. American Journal of Plant Sciences 4:20922111. https://doi.org/10.4236/ajps.2013.411261

Lee S, Wolberg G, Shin SY (1997) Scattered Data Interpolation with Multilevel B-Splines, IEEE Transactions On Visualisation And Computer Graphics 3:228-244. https://doi.org/10.1109/2945.620490

López De Heredia U, Duro-García MJ, Soto A (2018) Leaf morphology of properties in Q. suber, Q. ilex and their hybrids using multivariate and geometric morphometric analysis. IForest 11: 90-98. https://doi.org/10.3832/ifor2577-010

López Lauenstein DA, Fernandez ME, Verga AR (2013) Drought stress tolerance of Prosopis chilensis and Prosopis flexuosa species and their hybrids.Trees 27:285-296. https://doi.org/10.1007/s00468-012-0798-0 
Mantel N (1967) The detection of disease clustering and a generalized regression approach. Cancer Research 27:209-220.

Mottura M, Finkeldey R, Verga AR, Gailing O (2005) Development and characterization of microsatellite markers for Prosopis chilensis and Prosopis flexuosa and cross-species amplification. Molecular Ecology Notes 5:487-489. https://doi.org/10.1111/j.1471-8286.2005.00965.x

Mottura MC (2006) Development of microsatellites in Prosopis spp. and their application to study the reproduction system. Doctoral Thesis. Library of Lower Saxony State and Georg-August University of Göttingen.

Oksanen J, Blanchet FG, Kindt R, Legendre P, O'Hara RB, Simpson GL, Solymos P, Stevens MHH, Wagner H (2011) "vegan: Community Ecology Package."

Palacios RA, Bravo LD (1981) Hibridización natural en Prosopis (Leguminosae) en la región chaqueña Argentina. Evidencias morfológicas y cromatográficas [Natural hybridization in Prosopis (Leguminosae) in the Chaco region of Argentina. Morphological and chromatographic evidence]. Darwiniana 23:3-35.

Palacios RA, Brizuela MM (2005) Flora Fanerogámica Argentina [Argentinian Fanerochemical Flora]. Subfamilia II: Mimosoideae part 4. Tribu VI: Mimoseae part b. Proflora 92: 1-25. CONICET, Córdoba, Argentina.

Pasiecznik NM, Felker P, Harris PJC, Harsh LN, Cruz G, Tewari JC, Cadoret K, Maldonado LJ (2001) The Prosopis juliflora-Prosopis pallida Complex: A Monograph. HDRA, Coventry, UK.pp 172. https://doi.org/10.1016/s0378-1127(02)00559-5

Peakall R, Smouse PE (2012) GenAIEx 6.5: genetic analysis in Excel. Population genetic software for teaching and research-an update. Bioinformatics 28:2537-2539. https://doi.org/10.1093/bioinformatics/bts460

Potts BM, Reid JB (1990) The evolutionary significance of hybridization in Eucalyptus. Evolution 44:2151- 2152 https://doi.org/10.1111/j.1558-5646.1990.tb04319.x

Pritchard JK, Stephens M, Donnelly PJ (2000) Inference of population structure using multilocus genotype data. Genetics 155:945-959.

QGIS Development Team (2018) QGIS Geographic Information System. Open Source Geospatial Foundation Project. http://qgis.osgeo.org".

Rousset F (2000). Genetic differentiation between individuals. J Evol Biol 13:5862. https://doi.org/10.1046/j.1420-9101.2000.00137.x

Rousset F (2008) Genepop007: a complete re-implementation of the genepop software for Windows and Linux." Molecular Ecology Resources 8:103-106. https://doi.org/10.1111/j.1471-8286.2007.01931.x

Saidman BO (1990) Isoenzyme studies on hybrid swarms of Prosopis caldenia and sympatric species. Silvae Genetica 39:5-8.

Saidman BO, Vilardi JC, Montoya S, Poggio L (1997) Genetic variability and ploidy level in species of Prosopis (Leguminosae). Boletín de la Sociedad Argentina de Botánica 32:217-225.

Saidman BO, Vilardi JC, Montoya S, Dieguez MJ, Hopp HE (1998) Molecular Markers: A tool for the understanding of the relationships among species of Prosopis (Leguminosae, Mimosoideae). In: Puri S (ed) Tree improvement: applied research and technology transfer. Science Publishers, Inc., Enfield, pp 312-324. ISBN1-57808-027-4

Smouse PE, Long JC, Sokal RR (1986) Multiple regression and correlation extensions of the Mantel Test of matrix correspondence. Systematic Zoology 35:627-632. https://doi.org/10.2307/2413122

Teich I, Verga A, Balzarini M (2014) Assessing spatial genetic structure from molecular marker data via principal component analyses: A case study in a Prosopis sp. forest. Advances in Bioscience and Biotechnology 5: 89-99. https://doi.org/10.4236/abb.2014.52013

Teich I, Mottura M, Verga A, Balzarini M (2015) Asociación entre variabilidad genética y fenotípica con ajuste por autocorrelación espacial en Prosopis [Association between genetic and phenotypic variability with adjustment by spatial autocorrelation in Prosopis]. Journal of Basic and Applied Genetics 26:63-74.

Van Oosterhout C, Hutchinson W, Wills DPM and Shipley P (2004) MICRO-CHECKER: Software for Identifying and Correcting Genotyping Errors in Microsatellite Data. Molecular Ecology Notes 4: 535-538. https://doi.org/10.1111/j.1471-8286.2004.00684.x

Vega MV, Hernández P (2005) Molecular evidence for natural interspecific hybridization in Prosopis. Agroforestry Systems 64:197-202. https://doi.org/10.1007/s10457-004-2028-2

Verga AR (1995) Genetische Untersuchungen an Prosopis chilensis und P. flexuosa (Mimosaceae) im trockenen Chaco Argentiniens. Göttingen Research
Notes in Forest Genetics. Abteilung für Forstgenetik und Forstpflanzenzüchtung der Universität Göttingen ISSN 0940-7103, no. 19.

Verga A (2005) Recursos genéticos, mejoramiento y conservación de especies del género Prosopis [Genetic resources, improvement and conservation of species of the genus Prosopis]. En: Norverto, C.A. (Ed.), Mejores árboles para más forestadores: el programa de producción de material de propagación mejorado y el mejoramiento genético en el Proyecto Forestal de Desarrollo. Buenos Aires, Argentina.

Volante JN, Alcaraz-Segura D, Mosciaroa MJ, Viglizzo EF, Paruelo JM (2012) Ecosystem functional changes associated with land clearing in NW Argentina. Agriculture, Ecosystems \& Environment 154:12-22. https://doi.org/10.1016/j.agee.2011.08.012 